\title{
UM RETRATO DO LADO POBRE DA AGRICULTURA FAMILIAR NO ESTADO DO RIO GRANDE DO SUL
}

\author{
A PHOTO OF POOR SIDE OF THE FAMILY FARM IN RIO \\ GRANDE DO SUL STATE
}

\author{
Joacir Rufino de Aquino \\ Universidade do Estado do Rio Grande do Norte/Campus de Assú - Assú - RN - Brasil
Marcio Gazolla
Universidade Tecnológica Federal do Paraná/Campus de Pato Branco - Pato Branco - SC - Brasil

Sergio Schneider

Universidade Federal do Rio Grande do Sul - Porto Alegre - RS - Brasil

\begin{abstract}
Resumo: O objetivo deste artigo é evidenciar a dimensão social e analisar as características socioeconômicas e produtivas dos agricultores familiares pobres, classificados, segundo as regras do Programa Nacional de Fortalecimento da Agricultura Familiar - PRONAF, como Grupo B, no Estado do Rio Grande do Sul - RS. Em termos teórico-metodológicos, recorreu-se a abordagem das capacitações de Amartya Sen e ao approach de Frank Ellis para reunir os elementos conceituais necessários ao entendimento das "múltiplas carências produtivas" desse grupo específico de agricultores. Os dados utilizados para fundamentar a análise são oriundos de tabulações especiais do Censo Agropecuário 2006 do Instituto Brasileiro de Geografia e Estatística - IBGE. A pesquisa mostra que os estabelecimentos agropecuários de baixa renda, enquadráveis no Grupo B do PRONAF, estavam presentes em todas as microrregiões do RS, chegando a englobar metade dos agricultores familiares em algumas áreas do estado e, aproximadamente, $30 \%$ do segmento no ano de 2006. Os resultados da investigação também apontam para a grande vulnerabilidade social desses produtores gaúchos em várias dimensões dos seus meios de vida (dotações de capital natural, físico, humano, social e financeiro), demonstrando que há necessidade de melhorias quantitativas e qualitativas em sua plataforma de ativos (acesso a terra, água, financiamentos e tecnologias), bem como em suas capacitações básicas (educação formal e nível de organização social). Palavras-chaves: Agricultores familiares pobres. PRONAF B. Teoria das Capacitações;. Rio Grande do Sul.
\end{abstract}

\begin{abstract}
The aim of this paper is to highlight the social dimension and analyze the socioeconomic and productive characteristics of the poor farmers, classified according to the rules of the PRONAF Group B in the state of Rio Grande do Sul (RS). In theoretical and methodological terms, we used the approach of capabilities Amartya Sen and the approach of Frank Ellis to gather conceptual elements necessary to the understanding of "multiple productive needs" of this particular group of farmers. The data used are from special tabulations from the 2006 Agricultural Census, IBGE. Research shows that the farms in lowincome classifiable in Group B of PRONAF are present in all the RS micro, coming to encompass half the farmers in some areas and approximately $30 \%$ of the segment in the state. Research results also point to the high social vulnerability of these gauchos producers in various dimensions of their livelihoods (appropriations of natural capital, physical, human, social and financial), demonstrating that there is need for improvement in its asset platform (access land, water, finance and technology) as well as in their basic training (formal education and level of social organization).
\end{abstract}

Keywords: Poor family farm. PRONAF B. Theory of Capabilities. Rio Grande do Sul. 


\section{Introdução}

O debate sobre a agricultura familiar se intensificou no Brasil a partir da segunda metade dos anos 1990, alcançando grande projeção nacional e internacional com repercussão em diferentes níveis (NIEDERLE; FIALHO; CONTERATO, 2014). Essa forma específica de produção está presente em todo o país, mas é na Região Sul que, historicamente, apresenta os melhores indicadores de produção e produtividade. De fato, os principais estudos sobre o tema mostram que a fração mais capitalizada da agricultura familiar nacional se encontra nos estados sulinos, dentre eles o RS. Mas nem todos os agricultores gaúchos são ricos e prósperos. Como acontece no contexto brasileiro, no interior desse segmento há uma "franja periférica", denominada por alguns de "setor de subsistência", que ainda é pouco conhecida do ponto de vista de sua heterogeneidade social (FAO/INCRA, 1995; DELGADO, 2005; GRANDO, 2011; WANDERLEY, 2014).

De maneira geral, os agricultores pobres são mais vulneráveis do que os seus "co-irmãos familiares". O que caracteriza esse grupo e o segmenta em relação às demais unidades familiares, conforme estudos recentes de Aquino et al. (2014) e Wanderley (2014), é a precariedade e insuficiência de seus ativos, especialmente o tamanho da área de terra disponível. Mas eles também se notabilizam por utilizar menos recursos tecnológicos, por possuir uma infraestrutura precária em suas propriedades e apresentar relações pontuais ou pouco intensas com os mercados agropecuários. Muitos desses estabelecimentos e famílias sobrevivem a partir das transferências de renda e programas sociais do Estado, como é o caso da Previdência Rural e do Programa Bolsa Família PBF. Tal quadro de precariedade tem ensejado uma calorosa discussão, que ecoa no Brasil e também no contexto gaúcho, sobre quais estratégias acionar para inserir o segmento nos processos de desenvolvimento rural.

A resposta a esse desafio envolve diferentes propostas de políticas públicas e algumas delas têm sido apresentadas em debates e publicações recentes. Há um segmento influente de analistas que sugerem que a saída para este grupo social seria uma combinação de políticas assistenciais e o suporte a uma contínua migração para os espaços urbanos pelo fato de que, nas cidades, o custo de oportunidade de sua força de trabalho seria melhor (ALVES; ROCHA, 2010; BUAINAIN et al., 2013). Outros, contudo, sustentam que os agricultores pobres deveriam ser inseridos em um processo mais geral de desenvolvimento rural, formulado a partir de políticas e programas que melhorassem o seu acesso a ativos produtivos, gerasse capacitações e fortalecesse a sua resiliência econômica e ambiental (GRISA; SCHNEIDER, 2014). Com efeito, seja qual for a solução apontada ou a expectativa de futuro do segmento de produtores albergados na base da pirâmide social do campo, é preciso aprofundar o entendimento sobre suas condições de reprodução econômica, haja vista que existem muitas lacunas relacionadas ao tema ${ }^{1}$.

Neste contexto, visando avançar na discussão, o objetivo deste artigo é caracterizar e analisar a situação dos agricultores familiares pobres, potencialmente enquadráveis no Grupo B do PRONAF, no RS. Além de quantificar este segmento e

\footnotetext{
${ }^{1} \mathrm{O}$ desafio de estudar, compreender e sugerir políticas sobre o lugar e o papel dos pequenos produtores familiares mais vulneráveis do rural brasileiro assume proporções ainda mais relevantes no contexto das recentes mudanças institucionais, representadas pela extinção do Ministério do Desenvolvimento Agrário - MDA mediante sua fusão ao Ministério do Desenvolvimento Social - MDS, em maio de 2016. A questão que fica em aberto é saber se o universo dos agricultores familiares mais empobrecidos será contemplado doravante apenas com políticas sociais, tais como o PBF, sendo desqualificados enquanto produtores rurais com alguma função econômica.
} 
mapear sua distribuição geográfica nas distintas microrregiões do estado, apresentam-se informações sobre seu perfil socioprodutivo e discutem-se as "múltiplas carências" de ativos e de capitais que determinam a condição de vulnerabilidade social dos mesmos, indicando pistas para a formulação de políticas públicas voltadas à reversão da realidade retratada.

Os dados utilizados na investigação são provenientes de tabulações especiais do Censo Agropecuário 2006 por meio das quais segmenta-se os estabelecimentos agrícolas segundo as diretrizes da Lei da Agricultura Familiar, tornando possível delimitar a agricultura familiar e a não familiar nas estatísticas do IBGE. Também se utilizaram as variáveis derivadas, desenvolvidas pela parceria deste órgão com o Ministério do Desenvolvimento Agrário (MDA), com as quais foi possível tipificar os agricultores familiares, segundo os grupos do PRONAF, partindo dos critérios de segmentação de renda definidos pelo Plano Safra 2006-07. As informações decorrentes desse recorte metodológico foram analisadas a partir das lentes teóricas da abordagem das capacitações, de Amartya Sen $(1981 ; 2000 ; 2001)$, e do enfoque interpretativo de Frank Ellis (2000) sobre os meios de vida (livelihoods).

A estrutura do texto está dividida em três seções além dessa introdução e das considerações finais. $\mathrm{Na}$ segunda seção é apresentado, muito brevemente, o enfoque teórico que serviu de base para a seleção das variáveis usadas na caracterização do público estudado. Na seção seguinte, apresenta-se a metodologia empregada para tipificar os estabelecimentos agropecuários e identificar os agricultores familiares pobres. Na quarta seção, por sua vez, são descritos os resultados da investigação, bem como é feita a análise e discussão dos indicadores censitários obtidos a partir do levantamento realizado.

\section{Abordagem das capacitações e dos meios de vida: aportes teóricos para entender o perfil da pobreza no campo}

A argumentação empreendida nessa pesquisa se apoia, em linhas gerais, na Teoria das Capacitações de Amartya Sen e no approach interpretativo dos meios de vida desenvolvido por Frank Ellis. Ambos aportes teóricos são usados para compreender as fragilidades sociais dos agricultores familiares pobres enquadrados no PRONAF B no RS.

Os dois conceitos centrais da Teoria das Capacitações de Sen $(2000 ; 2001)$ são "funcionamentos" e "capacitações". Por funcionamentos, Sen (2000) entende as várias coisas que uma pessoa pode "ser" ou "fazer", sendo identificadas nos aspectos mais simples, como não passar fome e estar bem nutrido, até aspectos mais complexos como a realização da autoestima. Já as capacitações envolveriam as liberdades instrumentais (meios) que um ser humano possui para gozar a vida segundo suas escolhas.

Nessa perspectiva, a pobreza é vista como uma situação em que a ausência de certas condições ou possibilidades impedem os indivíduos de ser e fazer o que desejam e, portanto, tornam-se privados de algumas liberdades efetivas. Ou seja, ela não é apenas uma situação de renda insuficiente (pobreza econômica), mas, sobretudo, uma situação de vulnerabilidade que decorre de carências no acesso a capacitações fundamentais, como saúde, educação, nutrição, segurança protetora, entre outras. Assim, segundo Sen (1981), a pobreza deve ser entendida em suas múltiplas dimensões e não apenas por aspectos relacionados à insuficiência de renda monetária.

Apoiando-se nos pressupostos ontológicos e filosóficos da teoria das capacitações de Sen, Frank Ellis elaborou um aporte analítico próprio para analisar as condições de vulnerabilidade das famílias rurais de países em desenvolvimento 
utilizando como indicadores as características dos meios de vida dessas famílias ${ }^{2}$. De acordo com Ellis (2000), as principais carências dos agricultores pobres estão associadas à precariedade da "plataforma de ativos ou estoques de capital" de que eles são detentores, tais como: capital natural (terra, água), capital físico (máquinas, equipamentos, insumos), capital humano (educação, assistência técnica), capital social (associações, cooperativas) e capital financeiro (renda, financiamentos). É essa precariedade no estoque de ativos/capitais que gera a vulnerabilidade e cria privações que impedem o exercício das capacitações necessárias ao bem-estar. Logo, a análise dos meios de vida que uma família possui permite saber se ela tem recursos e capacidades para enfrentar situações adversas, como os choques climáticos e os riscos inerentes à atividade agrícola, que variam segundo as condições ambientais e socioeconômicas de cada espaço territorial.

Desse modo, ser pobre não se resume a ter baixa renda ou pouco dinheiro. Mais do que isso, a pobreza consiste em ter uma baixa ou insuficiente dotação de ativos e de capitais capazes de permitir a construção de estratégias de ação e reação que gerem resiliência e fortalecimento dos meios de ganhar a vida a partir do trabalho. É por isso que unidades produtivas que possuem um estoque de recursos mais amplo e diversificado reúnem melhores condições para enfrentar adversidades e permanecer ao longo do tempo (ELLIS, 2000).

A partir dessas considerações gerais e com o objetivo de operacionalizar os conceitos descritos, montou-se um quadro analítico composto por um conjunto de indicadores do Censo Agropecuário 2006, exposto na sequência (Quadro 1), que considera o pentágono de capitais constitutivos da plataforma de ativos presente no esquema dos meios de vida proposto por Ellis (2000). É com base nesses indicadores e suas variáveis que se analisará os aspectos que determinam a situação vivenciada pelos agricultores familiares pobres do Grupo B do PRONAF no Estado do RS.

\footnotetext{
${ }^{2}$ Para uma análise detalhada sobre a evolução e os principais conceitos da abordagem dos meios de vida e sua relação com os processos de desenvolvimento rural, sugere-se consultar os trabalhos de: Freitas (2015), Perondi e Schneider (2012), Perondi (2014) e Scoones (2009). Na mesma direção, o livro recente de Scoones (2015) atualiza e amplia a perspectiva de F. Ellis aqui utilizada.
} 
Quadro 1. Dimensões dos meios de vida e variáveis utilizadas para caracterizar a situação dos agricultores familiares pobres no RS

\begin{tabular}{|c|l|}
\hline $\begin{array}{c}\text { Plataforma de Ativos } \\
\text { (Capitais) }\end{array}$ & \multicolumn{1}{c|}{ Variáveis do Censo Agropecuário 2006} \\
\hline Natural & $\begin{array}{l}\text { Área total e média dos estabelecimentos (em hectares); Fontes d'água nos } \\
\text { estabelecimentos. }\end{array}$ \\
\hline Físico & $\begin{array}{l}\text { Uso de força de tração animal; Uso de força de tração mecânica; Uso de adubos em } \\
\text { lavouras; Uso de irrigação; Cultivo de agricultura orgânica. }\end{array}$ \\
\hline Humano & $\begin{array}{l}\text { Total de pessoas ocupadas no estabelecimento; Composição do pessoal ocupado; } \\
\text { Idade do chefe do estabelecimento; Nível de instrução; Acesso à assistência técnica } \\
\text { e extensão rural. }\end{array}$ \\
\hline Social & Nível de organização social (em sindicatos, associaçães e cooperativas). \\
\hline Financeiro & $\begin{array}{l}\text { Valor da produção agropecuária; Participação e valor da produção para } \\
\text { autoconsumo; Acesso a financiamentos rurais; Receitas agropecuárias e Outras } \\
\text { receitas do estabelecimento. }\end{array}$ \\
\hline
\end{tabular}

Fonte: Elaboração dos autores a partir do approach de Ellis (2000).

Nesses termos, a proposta analítica adotada visa a compreender os diferentes fatores que determinam a pobreza dos agricultores familiares gaúchos, buscando evidenciar as múltiplas carências produtivas que tolhem suas chances de ascensão social e inibem seu papel como agentes do processo de desenvolvimento rural. No entanto, antes de avançar na investigação, faz-se necessário especificar melhor os critérios adotados para classificar esse público particular nas estatísticas censitárias brasileiras.

\section{Metodologia $^{3}$}

\subsection{Delimitação da agricultura familiar e não familiar no Censo Agropecuário 2006}

Os dados utilizados para fundamentar a análise proposta neste artigo são provenientes do Censo Agropecuário realizado pelo IBGE em 2007, cuja data de referência foi 31 de dezembro de 2006. Todavia, é pertinente esclarecer que eles apresentam um caráter particular em relação a outros indicadores similares disponíveis nos sítios eletrônicos oficiais até recentemente, pois foram obtidos a partir de tabulações especiais da segunda apuração das estatísticas censitárias disponibilizadas para consulta pública no Sistema IBGE de Recuperação Automática de Dados - SIDRA apenas no final de 2012.

O processo de elaboração das tabulações especiais, de forma específica, envolveu um conjunto de etapas sucessivas e complementares entre si. De posse dos dados primários da segunda apuração do Censo Agropecuário 2006, os técnicos do IBGE e do MDA procederam, inicialmente, à separação dos estabelecimentos recenseados em Familiares e Não Familiares. Nessa fase, recorreu-se inteiramente à metodologia inovadora desenvolvida pela parceria entre as instituições citadas, que delimitou o universo familiar no Brasil por meio da aplicação dos critérios da Lei 11.326/2006 - Lei da Agricultura Familiar.

\footnotetext{
${ }^{3}$ Seção elaborada, integralmente, a partir de Aquino et al. (2011; 2014) e Aquino e Lacerda (2014).
} 
Desse modo, com base nos critérios da mencionada Lei, foram considerados "Familiares" todos os produtores que, segundo Del Grossi e Marques (2010), IBGE (2009), IBGE/SIDRA (2012),

i) não detivessem estabelecimentos com área maior que quatro módulos fiscais;

ii) utilizassem predominantemente a mão de obra da própria família nas atividades do seu estabelecimento ou empreendimento;

iii) tivessem a renda familiar predominantemente originada de atividades vinculadas ao próprio estabelecimento; e

iv) dirigissem o estabelecimento em conjunto com sua família.

Por exclusão, os estabelecimentos não enquadrados nos critérios descritos foram classificados como não familiares. Em outros termos, eram estabelecimentos com mais de quatro módulos fiscais, tocados majoritariamente por trabalhadores assalariados e dirigidos por administradores ou capatazes. Nessa perspectiva, em sintonia com estudos anteriores (FAO/INCRA, 2000; KAGEYAMA; BERGAMASCO; OLIVEIRA, 2013), os estabelecimentos foram definidos não por sua área/tamanho, mas por suas relações sociais de produção, se familiares ou do tipo patrão-empregado.

É importante sublinhar ainda que o trabalho coletivo do IBGE/MDA não se resumiu apenas a delimitar os agricultores familiares no Brasil. Posteriormente à apuração dos primeiros resultados do recenseamento, também foi realizado um esforço paralelo no sentido de captar as diferenças internas do segmento, usando a legislação vigente na distribuição do crédito rural do PRONAF como parâmetro de estratificação.

\subsection{Classificação dos agricultores familiares pobres do Grupo B a partir das normas do PRONAF vigentes em 2006/2007}

Após a identificação dos agricultores familiares, o passo seguinte na construção das tabulações especiais foi extrair das estatísticas do Censo Agropecuário 2006 o conjunto formado pelos estabelecimentos que se enquadravam nas normas oficiais da política de crédito do PRONAF, ou seja, o público potencial do programa. Tal procedimento viabilizou-se através de outra inovação do banco de dados criado pela parceria do IBGE com o MDA, que permitiu a inserção de variáveis derivadas nos dados censitários, possibilitando tipificar os produtores familiares em "pronafianos" (Familiares PRONAF) e "não pronafianos" (Familiares não PRONAF).

Desse modo, adotando as normas operacionais do crédito rural vigentes no Plano Safra 2006/2007 como parâmetro, foram considerados "pronafianos" apenas os estabelecimentos enquadrados na Lei 11.326 que: obtivessem rendimentos anuais até $\mathrm{R} \$ 80$ mil e usassem predominantemente o trabalho da família ou, no máximo, dois empregados permanentes. Tipificados os grupos de "pronafianos", os demais estabelecimentos familiares, com rendimentos acima de $\mathrm{R} \$ 80$ mil e com mais de dois empregados permanentes, foram considerados "não pronafianos".

Os estabelecimentos familiares "pronafianos" foram estratificados nos cinco grupos que formavam o público potencial do PRONAF em $2006^{4}$. Entre eles, foram caracterizados como Grupo $\mathrm{B}$ todos aqueles agricultores que atendessem às seguintes condições (DEL GROSSI, 2011; IBGE/SIDRA, 2012; MDA/SAF/PRONAF, 2006):

\footnotetext{
${ }^{4}$ De 2000 a 2008 o público potencial do PRONAF era composto pelos grupos "A" (assentados), "B" (pobres), "C" (intermediários), "D" e "E" (consolidados). Cada um deles, de acordo com o seu nível de renda, recebia um tratamento diferenciado no momento da concessão do crédito ofertado em condições especiais. A partir da safra 2008/2009, as regras do programa foram alteradas e os estratos "C", "D" e "E" foram agregados em um único grupo denominado de "agricultores familiares" ou de "Grupo Variável" (MATTEI, 2008).
} 
i) explorassem parcela de terra na condição de proprietário, posseiro, arrendatário ou parceiro;

ii) residissem na propriedade ou em local próximo;

iii) não dispusessem, a qualquer título, de área de terra superior a 4 (quatro) módulos fiscais quantificados segundo a legislação em vigor;

iv) obtivessem, no mínimo, 30\% (trinta por cento) da renda familiar da exploração agropecuária e não agropecuária do estabelecimento;

v) tivessem o trabalho familiar como base na exploração do estabelecimento e não detivessem empregados permanentes; e

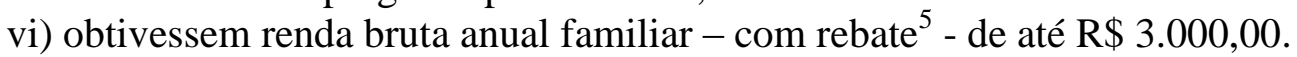

A aplicação simultânea de cada um desses critérios de classificação resultou na identificação de dois segmentos distintos de agricultores familiares: o primeiro, formado pelos produtores mais pobres que são objeto deste estudo, abrangendo todos os estabelecimentos recenseados com renda bruta anual familiar "rebatida" igual ou inferior a R \$ 3 mil (Familiar [Grupo B]); e, o segundo, constituído pelos assentados da reforma agrária e outros agricultores familiares "pronafianos" e "não pronafianos" com renda superior a $\mathrm{R} \$ 3$ mil por ano (Familiar [exceto Grupo B]).

Os parâmetros de estratificação detalhados nos parágrafos anteriores permitiram aos técnicos do IBGE e do MDA, finalmente, gerar informações individualizadas referentes ao segmento de agricultores familiares pobres presente na estrutura agrária brasileira e do RS. A partir daí, foram usadas técnicas estatísticas para realizar o cruzamento das variáveis da segunda apuração do Censo Agropecuário 2006 e, com isso, gerar o banco de dados sobre as condições de reprodução social dessa categoria específica de produtores. A síntese resultante dos critérios adotados pode ser visualizada no Quadro 2, que indica ser possível aprofundar o entendimento da diversidade que existe na agropecuária brasileira e sul-rio-grandense por meio das "tabulações especiais" que foram construídas a partir dos dados censitários disponíveis no SIDRA (http://www.sidra.ibge.gov.br/).

Quadro 2. Segmentação dos estabelecimentos agropecuários a partir da Lei da Agricultura Familiar e das normas do PRONAF vigentes no Plano Safra 2006/2007

\begin{tabular}{|c|l|l|}
\hline \multirow{2}{*}{$\begin{array}{c}\text { Estabelecimentos agropecuários - } \\
\text { Censo Agropecuário 2006 }\end{array}$} & \multirow{2}{|c|}{ Não Familiar } \\
\cline { 2 - 3 } & Familiar - Lei 11.326 & Familiar (Grupo B) \\
\cline { 2 - 3 } & & Familiar (exceto Grupo B) \\
\hline
\end{tabular}

Fonte: Elaboração dos autores a partir de Aquino et al. (2014).

Os números obtidos por meio dos procedimentos destacados foram rigorosamente corrigidos e vários indicadores foram atualizados em relação à publicação original do IBGE (2009), representando um resultado importante na parceria interinstitucional deste órgão com o MDA (DEL GROSSI, 2011; IBGE/SIDRA, 2012). A partir deles, buscar-se-á demonstrar nas próximas seções a heterogeneidade e pobreza existente nos espaços rurais do RS no período analisado.

\footnotetext{
${ }^{5}$ Define-se renda bruta anual familiar como sendo aquela proveniente de atividades agropecuárias e não agropecuárias desenvolvidas no interior do estabelecimento e/ou fora dele por qualquer membro da família. No seu cálculo, contabiliza-se $100 \%$ das rendas não rurais, excluídos o valor dos benefícios sociais e os proventos previdenciários decorrentes das atividades rurais. Além disso, para efeito de enquadramento dos grupos de "pronafianos" ("B", "C", "D" e "E"), a norma do Conselho Monetário Nacional - CMN que regulava as operações de crédito na safra 2006/2007 ainda determinava que a renda bruta familiar devia ser "rebatida" em algumas atividades específicas, ou seja, ter descontos, aproximando-se assim da renda líquida do empreendimento (DEL GROSSI, 2011).
} 


\section{Participação dos agricultores familiares pobres na agropecuária gaúcha}

A estrutura agropecuária do RS é constituída por agricultores que apresentam distintos graus de capitalização e de qualidade de vida. Para evidenciar esse aspecto, a Tabela 1 apresenta a divisão dos estabelecimentos rurais entre agricultores familiares e não familiares, bem como entre familiares "pobres" e "não pobres". A agricultura não familiar (ou patronal) gaúcha respondia, em 2006, por 14,30\% dos estabelecimentos e a familiar, por $85,70 \%$ dos mesmos. Dentro deste último contingente, a maioria dos agricultores são familiares (exceto PRONAF Grupo B), atingindo a cifra de 60,72\%. O público familiar do Grupo $\mathrm{B}$, de forma isolada, abrange quase $1 / 4$ da agricultura sul-riograndense (24,98\%), demonstrando a expressiva representatividade dos 110.284 estabelecimentos da categoria nas áreas rurais do estado.

Tabela 1. Segmentação da estrutura da agropecuária do RS e participação do Grupo B do PRONAF no total de estabelecimentos - 2006

\begin{tabular}{l|c|c}
\hline Tipos de Agricultura & $\mathbf{N}^{\mathbf{0}}$ de Estabelecimentos & $\%$ \\
\hline Não Familiar & 63.119 & 14,30 \\
Familiar - Lei 11.326 & 378.353 & 85,70 \\
Familiar (Grupo B) & 110.284 & 24,98 \\
Familiar (exceto Grupo B) & 268.069 & 60,72 \\
\hline \multicolumn{2}{|c|}{ Total } & $\mathbf{1 0 0 , 0 0}$ \\
\hline Fonte: Tabulação especial da segunda apuração do Censo Agropecuário 2006 (IBGE/SIDRA, 2012). \\
Nota: Dados organizados pelos autores.
\end{tabular}


No que se refere à participação relativa do Grupo B do PRONAF no interior da agricultura familiar do RS, a Tabela 2, a seguir, traz a espacialização dos estabelecimentos recenseados pelo IBGE para as diferentes microrregiões do estado, sendo possível identificar onde estes "tipos" de agricultores estavam mais ou menos presentes na geografia gaúcha no ano do censo. Em algumas microrregiões, os estabelecimentos familiares de baixa renda ostentam percentuais altos de participação (inclusive acima de $50 \%$ dos estabelecimentos existentes na microrregião) como é o caso do Litoral Lagunar $(51,25 \%)$ e de Osório (50,92\%). Em outras, possuem percentuais próximos da metade das unidades de produção: São Jerônimo (49,02\%), Serra do Sudeste $(45,74 \%)$, Montenegro $(45,58 \%)$, Vacaria $(44,44 \%)$, Gramado-Canela $(44,20 \%)$, Porto Alegre (43,18\%) e Campanha Ocidental $(42,51 \%)$.

Dentre essas microrregiões, chama a atenção a grande presença dos agricultores da "franja periférica" no eixo Porto Alegre/Serra Gaúcha/Litoral Norte, consideradas as áreas mais desenvolvidas economicamente e com os melhores indicadores sociais do estado. Entretanto, parcela expressiva de seus agricultores familiares apresentavam baixos níveis de renda e, por decorrência, altas taxas de pobreza rural.

Por outro lado, como microrregiões em que os estabelecimentos do Grupo B do PRONAF estão menos presentes, destacam-se Não-Me-Toque (11,65\%), Santa Cruz do Sul (14,18\%), Passo Fundo (18,02\%), Camaquã (19,50\%), Erechim (19,68\%) e Ijuí $(19,93 \%)$, evidenciando que nestes espaços havia menos agricultores familiares pobres com rendimentos inferiores a $\mathrm{R} \$ 3 \mathrm{mil} / \mathrm{ano}$. Nas demais regiões do RS, figuram percentuais intermediários de 20 a $40 \%$ de presença dos estabelecimentos de agricultores familiares "pronafianos" do Grupo B, sendo 19 microrregiões nesta situação. 
Tabela 2 - Participação dos estabelecimentos do Grupo B do PRONAF no interior da agricultura familiar por microrregiões do RS - 2006

\begin{tabular}{|c|c|c|c|}
\hline Microrregiões & $\begin{array}{c}\text { Familiar - Lei } 11.326 \\
\text { (A) }\end{array}$ & $\begin{array}{c}\text { Grupo B } \\
\text { (B) }\end{array}$ & $\begin{array}{c}\% \\
(\mathrm{~B} / \mathrm{A}) \\
\end{array}$ \\
\hline Litoral Lagunar & 3.171 & 1.625 & 51,25 \\
\hline Osório & 12.317 & 6.272 & 50,92 \\
\hline São Jerônimo & 6.079 & 2.980 & 49,02 \\
\hline Serras de Sudeste & 11.386 & 5.208 & 45,74 \\
\hline Montenegro & 9.905 & 4.515 & 45,58 \\
\hline Vacaria & 7.404 & 3.290 & 44,44 \\
\hline Gramado-Canela & 6.398 & 2.828 & 44,20 \\
\hline Porto Alegre & 7.283 & 3.145 & 43,18 \\
\hline Campanha Ocidental & 6.286 & 2.672 & 42,51 \\
\hline Campanha Central & 4.078 & 1.596 & 39,14 \\
\hline Santa Maria & 11.379 & 4.453 & 39,13 \\
\hline Lajeado-Estrela & 20.428 & 7.125 & 34,88 \\
\hline Campanha Meridional & 3.413 & 1.184 & 34,69 \\
\hline Pelotas & 18.980 & 6.534 & 34,43 \\
\hline Jaguarão & 1.911 & 632 & 33,07 \\
\hline Santo Ângelo & 14.856 & 4.506 & 30,33 \\
\hline Soledade & 8.185 & 2.420 & 29,57 \\
\hline Santiago & 6.764 & 1.882 & 27,82 \\
\hline Restinga Seca & 7.846 & 2.125 & 27,08 \\
\hline Carazinho & 10.447 & 2.798 & 26,78 \\
\hline Cachoeira do Sul & 9.091 & 2.416 & 26,58 \\
\hline Frederico Westphalen & 23.091 & 5.965 & 25,83 \\
\hline Caxias do Sul & 13.540 & 3.350 & 24,74 \\
\hline Três Passos & 18.871 & 4.621 & 24,49 \\
\hline Sananduva & 8.932 & 2.097 & 23,48 \\
\hline Cerro Largo & 9.558 & 2.237 & 23,40 \\
\hline Guaporé & 11.536 & 2.660 & 23,06 \\
\hline Santa Rosa & 16.415 & 3.437 & 20,94 \\
\hline Cruz Alta & 9.069 & 1.888 & 20,82 \\
\hline Ijuí & 11.074 & 2.207 & 19,93 \\
\hline Erechim & 17.659 & 3.476 & 19,68 \\
\hline Camaquã & 8.327 & 1.624 & 19,50 \\
\hline Passo Fundo & 14.143 & 2.549 & 18,02 \\
\hline Santa Cruz do Sul & 25.441 & 3.607 & 14,18 \\
\hline Não-Me-Toque & 3.090 & 360 & 11,65 \\
\hline Total do RS & 378.353 & 110.284 & 29,15 \\
\hline
\end{tabular}

De maneira geral, o que se pode afirmar com base nos dados elencados é que ainda há muitos agricultores familiares pobres no RS, em média quase $1 / 3$ do total $(29,15 \%)$, os quais viviam em situação de vulnerabilidade social, cujos detalhes serão destacados nas subseções seguintes. Ressalta-se que o quadro de pobreza de uma parcela da população rural gaúcha já havia sido identificado por outros estudos (CASTRO, 2011; SCHNEIDER; FIALHO, 2000; WAQUIL, 2013), porém, utilizando uma base metodológica distinta, o que significa que a análise proposta neste artigo, ao enfocar exclusivamente a realidade dos agricultores familiares pobres, conforme as variáveis organizadas no Quadro 1, representa um avanço nas discussões sobre as condições de reprodução social deste grupo no contexto agrário estadual.

\section{A baixa dotação de capital natural e de capital físico/construído nos estabelecimentos do Grupo B}


Quando se analisa a situação socioeconômica dos agricultores familiares pobres, percebe-se, em princípio, que eles apresentam uma baixa dotação de capital natural em suas unidades produtivas. De fato, embora representem $25 \%$ dos estabelecimentos agropecuários do RS (Tabela 1), os produtores do Grupo B dispõem apenas de uma área de 1.144.033 ha, ou seja, 5,63\% dos mais 20,3 milhões de hectares mapeados pelo Censo Agropecuário 2006 no estado (IBGE/SIDRA, 2012).

Outra variável que corrobora a situação de precariedade dos agricultores familiares do Grupo B é a pequena área média de terra que eles têm à disposição, como exposto no Gráfico 1. Nele, percebe-se que a agricultura não familiar é a que possuía a maior área média, 224,47 ha, muito próxima à média total de todos os estabelecimentos agropecuários do RS, que era de 253,55 ha. Já a agricultura familiar (exceto Grupo B) detinha uma área média de 18,71 ha. Os familiares do Grupo B, por sua vez, eram os que possuíam as menores áreas médias: 10,37 ha.

Gráfico 1. Área média (em hectares) dos estabelecimentos agropecuários do Rio Grande do Sul - 2006

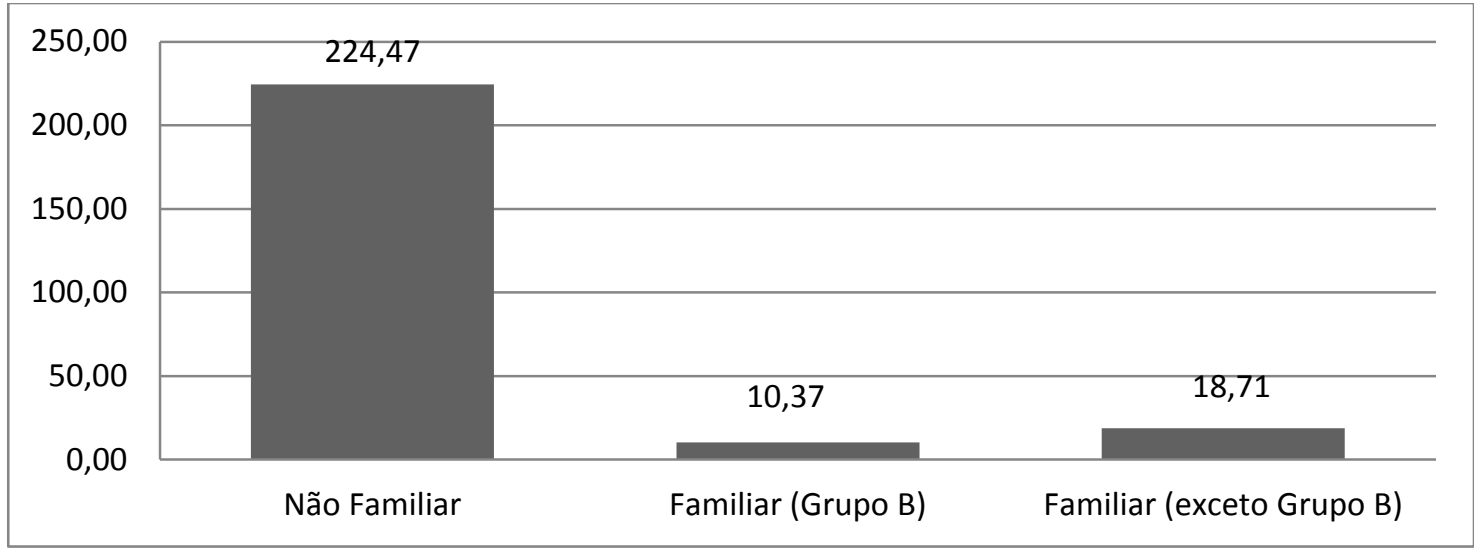

Fonte: Tabulação especial da segunda apuração do Censo Agropecuário 2006 (IBGE/SIDRA, 2012). Nota: Dados organizados pelos autores.

A terra é um ativo importante para o desenvolvimento das diversas atividades agropecuárias, pois ela representa a base dos processos biológicos de produção de alimentos. Assim, o tamanho reduzido das propriedades atua como um fator bloqueador das potencialidades dos agricultores pobres. Isso explica, em parte, a baixa produção agropecuária desse grupo e também a sua busca por outros tipos de receitas complementares que não passam necessariamente pela produção agrícola, como será discutido adiante.

A observação anterior ganha relevo quando se considera que a realidade fundiária do segmento de baixa renda é bem mais precária do que parece ser à primeira vista pelo simples cálculo da média estatística. Na Tabela 3, isso fica claro quando estratifica-se a área desses agricultores, pois evidencia-se que a grande maioria possuía extensões de terra ainda menores do que a média, uma vez que $63,73 \%$ das propriedades deste grupo específico estava abaixo do estrato de área de 10 ha. Outros 30,17\% dos membros da categoria eram detentores de áreas relativamente maiores, que variavam de 10 a 50 ha, sendo consideradas de porte adequado para o desenvolvimento de atividades agropecuárias. Um pequeno percentual, em torno de 3\% dos agricultores, detinham propriedades maiores que 50 ha e outros eram agricultores considerados sem área.

Tabela 3. Estratificação por grupos de área total dos estabelecimentos familiares do Grupo B do PRONAF no Rio Grande do Sul - 2006 


\begin{tabular}{l|c|c|c}
\hline Estrato de área (ha) & $\mathbf{N}^{\mathbf{0}}$ de Estabelecimentos & $\mathbf{\%}$ & \% Acumulado \\
\hline $0-5$ & 46.424 & 42,09 & 42,09 \\
$5-10$ & 23.859 & 21,63 & 63,73 \\
$10-50$ & 33.269 & 30,17 & 93,90 \\
$50-100$ & 2.924 & 2,65 & 96,55 \\
Mais de 100 & 400 & 0,36 & 96,91 \\
Produtor sem área & 3.408 & 3,09 & 100,00 \\
\hline Total & $\mathbf{1 1 0 . 2 8 4}$ & $\mathbf{1 0 0 , 0 0}$ & - \\
\hline \\
Fonte: Tabulação especial da segunda apuração do Censo Agropecuário 2006 (IBGE/SIDRA, 2012). \\
Nota: Dados organizados pelos autores.
\end{tabular}

Os indicadores censitários evidenciam, então, que a maior parte dos "pronafianos" pobres possuía uma baixa dotação do ativo terra, indicando que seus estabelecimentos poderiam ser chamados de "minifúndios", conforme a designação adotada pelo Estatuto da Terra. Isso porque sua área era inferior ao módulo rural, ou seja, estava abaixo do mínimo necessário para que uma família pudesse prover sua sobrevivência praticando exclusivamente a agricultura ${ }^{6}$. Registre-se que no estudo de Schneider e Fialho (2000) também se atribui parte da pobreza rural gaúcha ao reduzido tamanho das propriedades de uma expressiva parcela da população do campo, corroborando a análise ora apresentada.

É importante sublinhar, contudo, que a terra não é o único ativo natural escasso no âmbito dos estabelecimentos de baixa renda. O Censo 2006 também revelou que tais produtores enfrentavam grandes dificuldades produtivas devido à ausência de fontes perenes de água em suas pequenas propriedades. De fato, pouco mais de 1/3 do público estudado $(34,61 \%)$ obtinha água de poços comuns, que são fontes abertas pelos próprios agricultores em suas propriedades rurais para o consumo humano. Em outros casos, os "pronafianos" pobres abasteciam-se por meio de cisternas $(8,82 \%)$ e de poços artesianos ou semiartesianos $(2,97 \%)$. Note-se que, quando somados, estes três percentuais não atingem $50 \%$ dos agricultores pobres identificados.

A análise de variáveis como extensão da área disponível e acesso a fontes de água indica, assim, que os agricultores familiares pobres possuem um baixo estoque de capital natural em seus estabelecimentos. Isso mostra que este grupo social apresenta fragilidades em relação a ativos que são estratégicos ao desempenho de seu papel enquanto produtores de alimentos. Assim sendo, no contexto sul-rio-grandense, a baixa dotação de recursos naturais representava um forte bloqueio às atividades produtivas dos agricultores familiares do Grupo B. Tal limite ganha contornos mais graves na medida em que se evidencia que a maioria do segmento apresentava também um baixo nível de capital físico/construído à disposição em suas unidades produtivas (Tabela 4).

Tabela 4. Características tecnológicas dos estabelecimentos familiares do Grupo B do PRONAF no Rio Grande do Sul - 2006

\begin{tabular}{l|c|c|c}
\hline \multicolumn{1}{c|}{ Variáveis } & $\begin{array}{c}\text { Grupo B } \\
\text { (A) }\end{array}$ & $\begin{array}{c}\text { Grupo B que utiliza } \\
\text { tecnologia (B) }\end{array}$ & $\begin{array}{c}\text { \% de acesso } \\
\text { (B/A) }\end{array}$ \\
\hline Uso de força de tração animal & 110.284 & 46.273 & 41,96 \\
Uso de força de tração mecânica & 110.284 & 32.153 & 29,15 \\
Uso de adubos em lavouras & 110.284 & 7.691 & 6,97 \\
Utiliza irrigação & 110.284 & 2.555 & 2,32 \\
Cultiva agricultura orgânica & 110.284 & 2.922 & 0,03 \\
\hline
\end{tabular}

\footnotetext{
${ }^{6} \mathrm{O}$ Módulo Rural é uma área de terra que é variável de município para município. No caso do RS, uma média aproximada para o estado seria em torno de 20 ha, o que demonstra que a maioria dos agricultores familiares do Grupo B possui apenas a metade da terra necessária para prover sua manutenção de forma adequada.
} 
Fonte: Tabulação especial da segunda apuração do Censo Agropecuário 2006 (IBGE/SIDRA, 2012). Nota: Dados organizados pelos autores.

Com efeito, em termos de variáveis tecnológicas, dentro desse grupo social específico, 41,96\% dos estabelecimentos faziam uso da tração animal em suas práticas de trabalho, sendo geralmente a utilização de juntas de bois a situação mais corriqueira encontrada. $\mathrm{O}$ uso de tração mecânica via pequenos e médios tratores estava presente em menos de 1/3 dos estabelecimentos (29,15\%). O emprego de adubos nas lavouras foi verificado em apenas $6,97 \%$ das propriedades recenseadas. Já a prática da irrigação estava presente tão somente em 3\% das unidades e a agricultura de base orgânica era quase inexistente no seio desse público $(0,03 \%)$.

Nesse contexto, os dados analisados revelam que o segmento de produtores estudados caracteriza-se pelo baixo uso e/ou não acesso a técnicas e tecnologias em suas pequenas propriedades, sinalizando as dificuldades dos mesmos em formar o capital físico/construído necessário ao desenvolvimento de suas atividades produtivas. Esse uso reduzido de tecnologias, convencionais ou não, também pode estar ligado à baixa produção agropecuária e às limitadas áreas de terras disponíveis, algo que desencoraja investimentos de maior monta em novas infraestruturas de produção, prevalecendo o trabalho manual.

\section{Capital humano e nível de organização social dos agricultores pobres}

A agropecuária é uma fonte importante de ocupação no campo gaúcho. A Tabela 5 indica que, em 2006, mais de 1,2 milhão de pessoas estavam ocupadas nos estabelecimentos agropecuários do estado. Desse universo, a agricultura familiar (exceto Grupo B) respondia pela maior parte do contingente de pessoas ocupadas, absorvendo $61,98 \%$ das mesmas. A agricultura não familiar aparece com quase $20 \%$ do pessoal ocupado (19,50\%), seguida de perto pelos familiares do Grupo B que abrigavam, em seu interior, 228.172 pessoas, ou seja, 18,52\% da população ocupada nos estabelecimentos sul rio-grandenses. Note-se, por este prisma que o público do Grupo B é bastante representativo, pois perfaz aproximadamente 1/5 dos agricultores gaúchos e assume percentuais muito próximos do restante do segmento, englobando $23 \%$ do pessoal ocupado na agricultura familiar do RS. Dito de outra forma: em torno de 1/4 da população albergada na agricultura familiar gaúcha era pobre na data do recenseamento do IBGE.

Tabela 5. Total de pessoas ocupadas nos estabelecimentos agropecuários do Rio Grande do Sul - 2006

\begin{tabular}{l|c|c}
\hline Tipos de agricultores & Pessoal Ocupado (PO) & \% \\
\hline Não Familiar & 240165 & 19,50 \\
Familiar (Grupo B) & 228172 & 18,52 \\
Familiar (exceto Grupo B) & 763.488 & 61,98 \\
\hline Total & $\mathbf{1 . 2 3 1 . 8 2 5}$ & $\mathbf{1 0 0 , 0 0}$ \\
\hline
\end{tabular}

Fonte: Tabulação especial da segunda apuração do Censo Agropecuário 2006 (IBGE/SIDRA, 2012). Nota: Dados organizados pelos autores.

Por conseguinte, os dados extraídos das tabulações especiais do Censo Agropecuário 2006 permitem visualizar que a maioria das pessoas ocupadas nas propriedades rurais era composta de membros do próprio grupo doméstico $(97,96 \%)$, evidenciando o caráter familiar da força de trabalho desta agricultura. Por sua vez, somente $2,04 \%$ dos ocupados eram pessoas não pertencentes ao núcleo familiar, 
possivelmente alguns trabalhadores contratados ou habitantes temporários dos estabelecimentos (IBGE/SIDRA, 2012).

Ainda no que concerne aos aspectos demográficos, a Tabela 6 reúne informações sobre a idade da pessoa que dirige os estabelecimentos do Grupo B. É possível observar, inicialmente, que quase a metade dos agricultores pobres $(47,01 \%)$ estava no estrato etário de 45 a 65 anos. Além disso, havia um percentual ligeiramente superior a $1 / 4(27,52 \%)$ no estrato mais elevado de idade, com mais de 65 anos. Outro grupo de agricultores, que perfaz $23,51 \%$, estava situado em estratos etários de 25 a 45 anos e uma reduzida parcela $(1,95 \%)$ era constituída por agricultores mais jovens, até 25 anos de idade.

Os números destacados demonstram que a maioria dos agricultores integrantes do Grupo B possuía uma idade avançada, pois a soma dos indivíduos na faixa etária acima dos 45 anos chegava a 67,53\%, o que sinaliza um processo de envelhecimento desta categoria de agricultores familiares, como outros estudos têm apontado para os espaços rurais (CAMARANO; ABRAMOVAY, 1998; ANDERSON; SCHNEIDER, 2014). Eles também ajudam a explicar o porquê da rubrica aposentadorias e pensões apresentar-se tão elevada junto a esse tipo de agricultura (Tabela 12 adiante).

Tabela 6. Idade da pessoa que dirige os estabelecimentos familiares do Grupo B do PRONAF no Rio Grande do Sul - 2006

\begin{tabular}{|c|c|c|}
\hline Faixa de Idade & $N^{0}$ de agricultores & $\%$ \\
\hline Menos de 25 anos & 2.153 & 1,95 \\
\hline De 25 a 45 anos & 25.933 & 23,51 \\
\hline De 45 a 65 anos & 51.848 & 47,01 \\
\hline De 65 a mais anos & 30.350 & 27,52 \\
\hline Total & 110.284 & 100,00 \\
\hline
\end{tabular}

Ademais, evidencia-se o gargalo associado à recomposição do capital humano remanescente nos espaços rurais gaúchos, pois a força de trabalho mais jovem era de apenas $1 / 4$ dos agricultores que restam no meio rural $(25,46 \%$, se somados os dois primeiros estratos da Tabela 6). Esse fenômeno social se manifesta em função da redução das taxas de fecundidade (menos crianças nascem) e devido à elevação da expectativa de vida da população mais velha, como indicam as projeções de Zuanazzi e Bandeira (2013), mas também é provocado pela migração dos rapazes e moças de baixa renda em direção às cidades em busca de melhores condições de vida e trabalho.

Para além da questão do envelhecimento, outro fator que caracterizava os agricultores familiares pobres do RS eram os baixos níveis educacionais. Conforme pode ser observado na Tabela 7 , mais de $70 \%$ dos agricultores deste grupo tinham apenas formação referente a Educação de Jovens e Adultos (EJA) ou o Ensino Fundamental Incompleto (71,37\%), mostrando o baixo nível de instrução formal da categoria na época. A situação é ainda mais preocupante quando se analisa a parcela de agricultores que não sabem ler e escrever $(8,59 \%)$, bem como aqueles que não possuem nenhum nível de instrução, mas que de alguma forma aprenderam a ler e escrever $(4,14 \%)$. Havia outros grupos com maiores níveis de escolaridade, como era o caso de $8,02 \%$ dos chefes de estabelecimentos que possuíam o Ensino Fundamental Completo ou outros tipos de formação (7,88\%), incluindo o Ensino Médio Completo, Técnico Agropecuário ou mesmo Cursos de Graduação.

Tabela 7. Nível de instrução da pessoa que dirige os estabelecimentos familiares do Grupo B do PRONAF no Rio Grande do Sul - 2006 


\begin{tabular}{l|c|c}
\hline Nível de instrução & $\mathbf{N}^{\mathbf{0}}$ de agricultores & \% \\
\hline Não sabe ler e escrever & 9.468 & 8,59 \\
Nenhum nível de instrução (apenas sabe ler e escrever) & 4.571 & 4,14 \\
EJA e Ensino Fundamental incompleto & 78.710 & 71,37 \\
Ensino Fundamental completo & 8.842 & 8,02 \\
Outros (*) & 8.693 & 7,88 \\
\hline Total & $\mathbf{1 1 0 . 2 8 4}$ & $\mathbf{1 0 0 , 0 0}$ \\
\hline
\end{tabular}

Fonte: Tabulação especial da segunda apuração do Censo Agropecuário 2006 (IBGE/SIDRA, 2012). (*)

$\mathrm{Na}$ categoria "Outros" foram incluídos os entrevistados que declararam ter graus de formação variados (Ensino Médio Completo, Técnico Agrícola Completo e Graduações).

Com efeito, o que se pode depreender da análise da Tabela 7 é que os agricultores familiares pobres do RS, além de possuírem idade avançada, também apresentavam baixos níveis de capital humano materializados em seus precários indicadores de escolaridade. Como Sen (2001) formulou, a educação é um dos meios fundamentais para os indivíduos poderem ampliar sua capacidade de "ser e agir". Assim, no caso dos "pronafianos" pobres, a melhoria da educação formal seria um avanço relevante, por exemplo, para lhes fornecer conhecimentos técnicos e produtivos visando a incrementar a produção agrícola. Além disso, um maior estoque de conhecimentos ampliaria suas chances de prospectar novas oportunidades de investimento e de mercado, bem como acessar outras fontes de renda não agrícolas que os ajudaria a adquirir maior resistência e capacidade de adaptação ao contexto social onde estão inseridos.

O Gráfico 2, por sua vez, mostra que a participação dos agricultores familiares do Grupo B do PRONAF em organizações coletivas também era extremamente reduzida. Isso porque quase a metade dos representantes da categoria não participava de organizações sociais da agricultura familiar, seja sindical, cooperativada ou outras entidades de classe $(46,90 \%)$. Uma parcela deles era membro de entidades de classe $(34,51 \%)$, a exemplo de Sindicatos de Trabalhadores Rurais - STRs, sendo o tipo de organização social mais popular entre os mesmos. Outra fração de agricultores familiares do Grupo B participava de cooperativas e entidades de classe (10,53\%) e um pequeno contingente fazia parte apenas de cooperativas $(8,06 \%)$.

Gráfico 2. Nível de organização social dos chefes dos estabelecimentos familiares do Grupo B do PRONAF no Rio Grande do Sul - 2006 (\%)

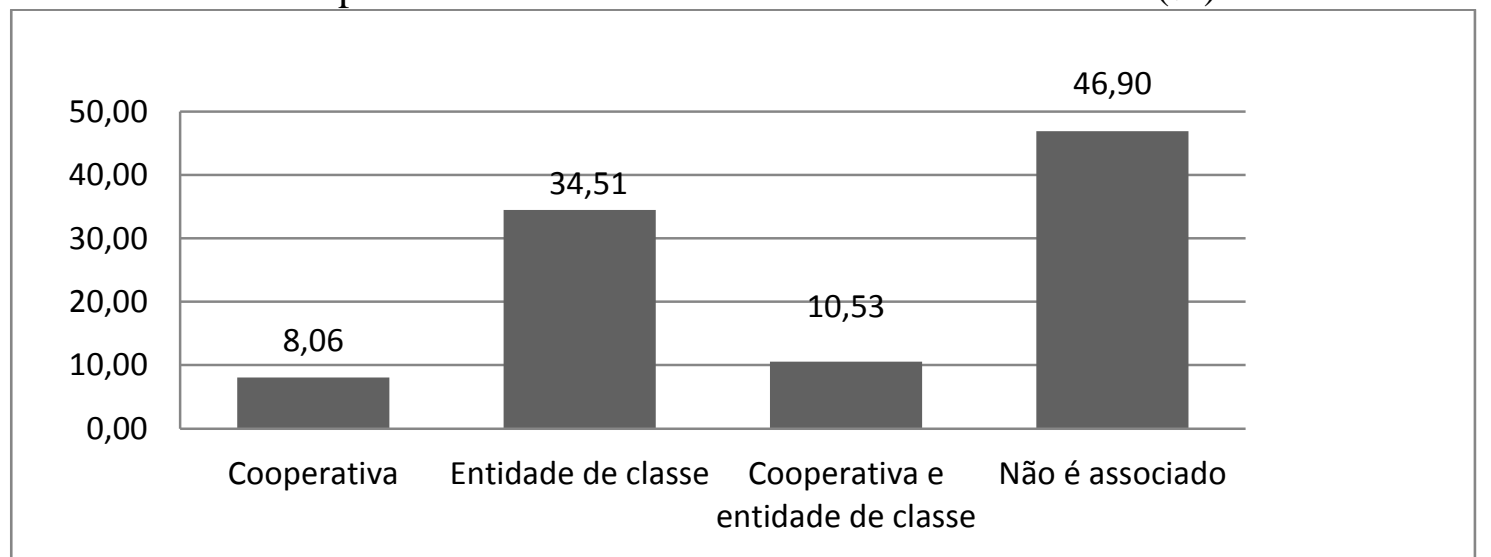

Fonte: Tabulação especial da segunda apuração do Censo Agropecuário 2006 (IBGE/SIDRA, 2012). Nota: Dados organizados pelos autores.

No total, o percentual de agricultores que participava de algum tipo de entidade coletiva equivalia a $53,10 \%$ do total, demonstrando que praticamente metade dos agricultores familiares pobres não estava ligada a organizações sociais. Como se sabe, 
as organizações sociais são importantes instrumentos para reivindicar e manter os direitos dos trabalhadores e agricultores, além de contribuir para aumentar o nível de formação e informação dos associados (PICOLOTTO, 2014). Também são instâncias de fornecimento de uma ampla base de serviços e podem ser estratégicas para aumentar a escala das pequenas iniciativas produtivas e econômicas e/ou diminuir custos de produção, comercialização e transação (ESTEVAM; MIOR, 2014).

As dificuldades relacionais dos produtores de baixa renda vêm à tona novamente quando se analisa sua interação com outros atores sociais fora do campo. Objetivando destacar esse aspecto, o Gráfico 3 traz o percentual de estabelecimentos familiares do Grupo B que receberam assistência técnica em 2006. A maioria dos produtores $(80,02 \%)$ declarou não ter recebido nenhum tipo de orientação das agências de assistência técnica e extensão rural e 14,36\% do público com renda até $\mathrm{R} \$ 3$ mil foi visitado por algum técnico agrícola apenas ocasionalmente durante o ano de referência do Censo. Do total pesquisado, somente 5,62\% contaram com o apoio regular dos órgãos de assistências técnica e extensão rural, evidenciando certo distanciamento das agências do Estado em relação aos agricultores pobres, que, teoricamente ${ }^{7}$, seriam o público prioritário do apoio institucional, inclusive, em termos técnicos e gerenciais, para superar suas fragilidades socioeconômicas.

Gráfico 3. Percentual de estabelecimentos do Grupo B em relação ao recebimento de orientação técnica no Rio Grande do Sul - 2006

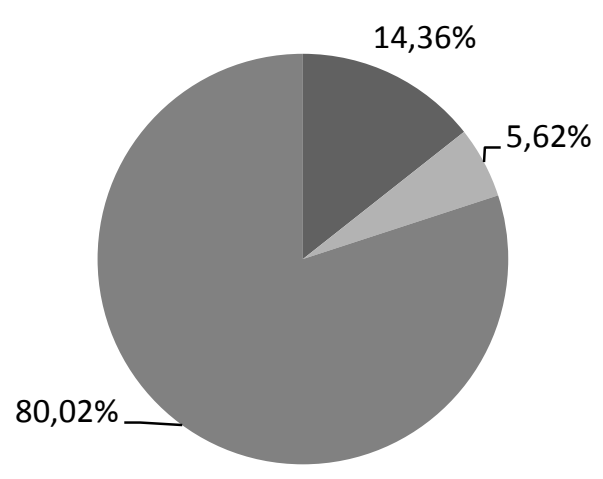

Recebeu ocasinalmente

Recebeu regularmente

Não recebeu

Fonte: Tabulação especial da segunda apuração do Censo Agropecuário 2006 (IBGE/SIDRA, 2012).

Os dados do nível de organização social e do acesso à assistência técnica dos agricultores Grupo B, analisados de forma conjunta, demonstram que estes produtores possuíam pouco capital social acumulado, uma vez que apresentavam relações limitadas com outras instituições e organizações sociais, carecendo aumentar suas interfaces com estes e outros atores, já que o acesso a um ativo ou capacitação é sempre mediado pelas instituições e pelas relações sociais que os mesmos estabelecem. Essa observação geral é importante no contexto analisado, tendo em vista que os estudos de Ellis (2000) indicam que a construção de portas de saída da pobreza rural depende do fortalecimento dos vínculos de confiança e reciprocidade dos agricultores pobres com outros atores sociais ou mesmo com instituições de apoio.

\footnotetext{
7 É claro que muitos agricultores possuem seus próprios conhecimentos e habilidades nas práticas agropecuárias, técnicas de produção e relacionamento com os mercados. O caso dos agricultores ecologistas da Serra Gaúcha (municípios de Ipê e Antônio Prado) é exemplar do modo como os agricultores familiares pouco ou nada necessitam dos serviços de assistência técnica e extensão rural prestados pelo Estado, pois são inovadores e buscam a autonomia em seu modo de vida e práticas de trabalho (OLIVEIRA; GAZOLLA; SCHNEIDER, 2011).
} 
Em resumo, as informações discutidas até aqui permitem afirmar que o universo de pessoas ocupadas nos estabelecimentos do Grupo B era extremamente representativo na agricultura familiar gaúcha no ano em foco, tanto em percentuais (era quase um terço da mesma), quanto em termos de membros do núcleo doméstico. Porém, esse contingente populacional reproduzia-se em um contexto de empobrecimento rural, baixos níveis educacionais e carência de apoio técnico. Esses fatores limitantes, especialmente os dois últimos, representavam privações à aquisição de maiores "capacitações" por parte do grupo de agricultores pesquisado, afetando, como será demonstrado a seguir, suas possibilidades de produzir excedente econômico agropecuário e gerar renda suficiente para usufruir de maiores níveis de qualidade de vida. 


\section{Produção agropecuária, receitas monetárias e capital financeiro}

O desempenho produtivo dos distintos segmentos que formam a agropecuária gaúcha pode ser mensurado pelo cálculo do Valor da Produção (VP) ${ }^{8}$. Observe-se, porém, que nem todas as unidades recenseadas pelo IBGE declararam atividade agropecuária em 2006, com variações entre o público estudado. Nesse sentido, a Tabela 8 indica que, no setor não familiar, o percentual de estabelecimentos com alguma produção alcançava 95,21\% e no segmento familiar (exceto o Grupo B), 99,53\%. No que diz respeito aos estabelecimentos da "franja periférica" (Grupo B), o percentual foi de $85,98 \%$, o mais baixo entre os três grupos destacados na tabela em foco.

Essa última informação enseja a hipótese de que a produção agropecuária não representava a única estratégia de reprodução socioeconômica dos membros do Grupo $\mathrm{B}$, os quais também utilizavam o meio rural como espaço de vida e sociabilidade com outros atores sociais ou outras funções da ruralidade contemporânea (WANDERLEY, 2009). Tal aspecto fica mais claro quando se especifica os dados desses agricultores por local de moradia, haja vista que $81,20 \%$ do total residiam no próprio estabelecimento e $7,20 \%$ viviam no rural, porém, fora da unidade produtiva. Além desses, apenas 11,60\% dos produtores familiares do Grupo B residiam em espaços urbanos próximos de seus respectivos locais de trabalho (IBGE/SIDRA, 2012).

Tabela 8. Percentual de estabelecimentos agropecuários do Rio Grande do Sul com Valor da Produção - 2006

\begin{tabular}{l|c|c|c}
\hline Tipos de agricultores & $\begin{array}{c}\mathbf{N}^{\mathbf{o}} \text { Estabelecimentos } \\
(\mathbf{A})\end{array}$ & $\begin{array}{c}\mathbf{N}^{\mathbf{0}} \text { Estab. com VP } \\
(\mathbf{B})\end{array}$ & $\begin{array}{c}\text { \% } \\
(\mathbf{B} / \mathbf{A})\end{array}$ \\
\hline Não Familiar & 63.119 & 60.095 & 95,21 \\
Familiar (Grupo B) & 110.284 & 94.817 & 85,98 \\
Familiar (exceto Grupo B) & 268.069 & 266.800 & 99,53 \\
\hline \multicolumn{1}{c|}{ Total } & $\mathbf{4 4 1 . 4 7 2}$ & $\mathbf{4 2 1 . 7 1 2}$ & $\mathbf{9 5 , 5 2}$ \\
\hline
\end{tabular}

Fonte: Tabulação especial da segunda apuração do Censo Agropecuário 2006 (IBGE/SIDRA, 2012).

A Tabela 9, de forma complementar, elenca alguns indicadores relativos ao valor monetário da produção agropecuária gerada no âmbito dos estabelecimentos estudados. Nela, percebe-se que a agricultura não familiar produzia pouco mais da metade da produção agropecuária do $\mathrm{RS}$, atingindo $51,40 \%$ do total, sendo a média por estabelecimento de $\mathrm{R} \$ 155.285,36$. Já a agricultura familiar (exceto Grupo B) era responsável por $47,44 \%$ da produção agropecuária gaúcha, o que equivalia a $R \$$ $32.285,76$ por estabelecimento.

A riqueza gerada pelos familiares de baixa renda (Grupo B), por seu turno, representava tão somente $1,16 \%$ do valor da produção estadual, proporcionando, em média, R\$2.220,04 por estabelecimento. Se convertidos em salários mínimos à época de 2006 , cujo valor era de $\mathrm{R} \$ 350,00$, esse montante correspondia a algo em torno de 6,34 salários mínimos anuais/estabelecimento, evidenciando a baixa capacidade produtiva desse segmento comparativamente aos demais tipos de agriculturas (restante dos familiares e não familiares). Tal resultado está intimamente relacionado à precariedade social da categoria, materializada no baixo estoque de capital natural e em outras carências nos demais meios de produção já discutidas anteriormente.

\footnotetext{
${ }^{8}$ O Valor da Produção - VP corresponde ao resultado da soma de três indicadores (IBGE, 2009): valor da produção vegetal, valor da produção animal e valor agregado da agroindústria (que é igual ao valor total dos produtos processados menos o valor das matérias-primas utilizadas).
} 
Tabela 9. Participação relativa e valor médio da produção dos estabelecimentos agropecuários do Rio Grande do Sul - 2006

\begin{tabular}{l|c|c|c|c|c}
\hline \multirow{2}{*}{ Tipos de agricultores } & \multicolumn{2}{|c|}{$\begin{array}{c}\text { No. de estab. c/ produção } \\
\text { no ano (Un.) }\end{array}$} & \multicolumn{2}{|c|}{$\begin{array}{c}\text { Valor da produção dos } \\
\text { estab. no ano (Mil Reais) }\end{array}$} & $\begin{array}{c}\text { Valor médio da } \\
\text { produção } \\
\text { (Em R\$) }\end{array}$ \\
\cline { 2 - 5 } & Número & \% & Número & \% & $155.285,36$ \\
Não Familiar & 60.095 & 14,25 & 9.331 .874 & 51,40 & $2.220,04$ \\
Familiar (Grupo B) & 94.817 & 22,48 & 210.498 & 1,16 & $32.285,76$ \\
Familiar (exceto Grupo B) & 266.800 & 63,27 & 8.613 .842 & 47,44 & $\mathbf{4 3 . 0 5 3 , 5 9}$ \\
\hline \multicolumn{1}{c|}{ Total } & $\mathbf{4 2 1 . 7 1 2}$ & $\mathbf{1 0 0 , 0 0}$ & $\mathbf{1 8 . 1 5 6 . 2 1 4}$ & $\mathbf{1 0 0 , 0 0}$ & \\
\hline
\end{tabular}

Fonte: Tabulação especial da segunda apuração do Censo Agropecuário 2006 (IBGE/SIDRA, 2012).

É pertinente sublinhar que, além dos pequenos valores produzidos, uma parcela significativa da produção do Grupo B era voltada para o autoconsumo, como mostra a Tabela $10^{9}$. Embora não seja direcionada ao mercado, esse tipo de produção constitui uma fonte de renda não monetária importante para as famílias rurais. De fato, na tabela em destaque, é possível verificar que nos estabelecimentos da agricultura familiar (exceto o Grupo B) era onde se encontrava o maior percentual de estabelecimentos com produção para autoconsumo $(88,29 \%)$. Em seguida, apareciam os estabelecimentos não familiares, com 77,32\%, acompanhados de perto pelo Grupo B, com 76,29\%, sendo os que menos apresentavam produção para autoconsumo.

Embora os estabelecimentos familiares do Grupo B correspondessem ao menor percentual de unidades que registram produção para autoconsumo, este grupo de agricultores era o que possuía uma produção para autoconsumo maior em relação à produção total do estabelecimento. Ressalte-se que o autoconsumo é fundamental para a dinâmica das propriedades rurais, especialmente as mais pobres e está diretamente relacionado aos processos de segurança alimentar e nutricional do grupo doméstico (GRISA; GAZOLLA; SCHNEIDER, 2010).

Nos estabelecimentos do Grupo B, em termos de valores, o autoconsumo abrangia $41,36 \%$ do total da produção, evidenciando que estes agricultores, por possuírem menos recursos monetários para comprar alimentos, procuravam produzir o máximo em suas propriedades rurais, visando tentar garantir minimamente o autoabastecimento da família. Os demais grupos de agricultores possuíam produção para autoconsumo em menor proporção em relação ao total: somente $13,30 \%$ entre os familiares (exceto Grupo B) e 3,49\% entre os não familiares (Tabela 10).

\footnotetext{
${ }^{9}$ Esta tabela foi obtida a partir da metodologia de cálculo utilizada no trabalho de Grisa, Schneider e Conterato (2014).
} 
Tabela 10. Participação dos estabelecimentos e valor da produção para o autoconsumo na agropecuária do Rio Grande do Sul - 2006

\begin{tabular}{l|c|c|c|c|c|c}
\hline Tipos de Agricultores & N. Estab. & $\begin{array}{c}\text { N. Est. c/ } \\
\text { prod. } \\
\text { Autoc. } \\
\text { (B) }\end{array}$ & $\begin{array}{c}\text { \% } \\
\text { (B/A) }\end{array}$ & $\begin{array}{c}\text { Valor Total } \\
\text { Produção } \\
\text { (Mil Reais) } \\
\text { (C) }\end{array}$ & $\begin{array}{c}\text { Val. Tot. } \\
\text { autoc. (Mil } \\
\text { Reais) } \\
\text { (D) }\end{array}$ & $\begin{array}{c}\text { \% } \\
\text { (D/C) }\end{array}$ \\
\hline Não Familiar & 63.119 & 48.801 & 77,32 & 9.331 .874 & 325.473 & 3,49 \\
Familiares (Grupo B) & 110.284 & 84.135 & 76,29 & 210.498 & 87.053 & 41,36 \\
Familiares (exceto & 268.069 & 236.679 & 88,29 & 8.613 .842 & 1.145 .398 & 13,30 \\
Gr.B) & & & & & & \\
\hline Total & $\mathbf{4 4 1 . 4 7 2}$ & $\mathbf{3 6 9 . 6 1 5}$ & $\mathbf{8 3 , 7 2}$ & $\mathbf{1 8 . 1 5 6 . 2 1 4}$ & $\mathbf{1 . 5 5 7 . 9 2 4}$ & $\mathbf{8 , 5 8}$ \\
\hline
\end{tabular}

Fonte: Tabulação especial da segunda apuração do Censo Agropecuário 2006 (IBGE/SIDRA, 2012). Nota: Dados organizados pelos autores.

Uma das explicações para os indicadores apresentados, que se deve adicionar às demais carências de capitais elencadas nas subseções precedentes, refere-se ao baixo nível de financiamentos obtidos pelo público do Grupo B. Conforme os números compilados das tabulações especiais do IBGE, a maioria absoluta dos agricultores familiares pobres gaúchos $(83,76 \%)$ não acessava nenhum tipo de linha de financiamento rural para fortalecer suas atividades econômicas e produtivas. Do total, apenas $16,24 \%$ conseguiram obter crédito rural de custeio ou investimento junto às instituições financeiras, seja via PRONAF, seja por meio de outras fontes (IBGE/SIDRA, 2012).

Com efeito, devido à baixa dotação de recursos produtivos e às pequenas áreas de terra disponíveis, os agricultores familiares pobres demonstravam dificuldades para produzir excedentes e se integrar às dinâmicas cadeias de comercialização agroindustrial existentes no RS. Sem receitas agropecuárias ou obtendo pequenas quantias de suas vendas, tais produtores tornavam-se dependentes de outras fontes de rendimentos para garantir sua reprodução social. Esta última afirmação é comprovada pelos dados da Tabela 11, a qual mostra que as receitas provenientes da comercialização da produção agropecuária dos estabelecimentos do Grupo do PRONAF eram menores do que $1 / 5$ das suas receitas totais, alcançando apenas $18,50 \%$. Já as demais receitas obtidas por estes agricultores perfaziam $81,50 \%$ dos rendimentos obtidos pelos mesmos, mostrando o papel relevante das outras fontes de rendimento para este segmento particular de produtores.

Tabela 11. Receitas obtidas pelos agricultores familiares do Grupo B do PRONAF no Rio Grande do Sul - 2006

\begin{tabular}{l|c|c}
\hline Receitas & Valores $(\mathbf{R} \$ \mathbf{1 . 0 0 0})$ & Percentual (\%) \\
\hline Receita Agropecuária $\left(^{*}\right)$ & 72.299 & 18,50 \\
Outras Receitas & 318.431 & 81,50 \\
\hline Receita Total & $\mathbf{3 9 0 . 7 3 0}$ & $\mathbf{1 0 0 , 0 0}$ \\
\hline
\end{tabular}

Fonte: Tabulação especial da segunda apuração do Censo Agropecuário 2006 (IBGE/SIDRA, 2012). (*) A Receita Agropecuária foi obtida pelo somatório do valor das vendas de: produtos vegetais, animais em geral e seus produtos, animais criados em cativeiros (jacaré, escargô, capivara e outros), húmus e esterco.

Na Tabela 12, é possível visualizar de forma mais precisa a composição e a importância exercida pelas receitas de outras fontes. Em primeiro lugar, figuram as receitas com aposentadorias e pensões, totalizando quase $85 \%$ das outras receitas obtidas pelo Grupo B. Nesse sentido, sobressai a importância da Previdência Social na manutenção dos agricultores pobres gaúchos, repetindo uma tendência verificada nas áreas rurais do Nordeste (AQUINO et al., 2014). Em segundo lugar, aparece a rubrica salários e outras receitas recebidas de fora dos estabelecimentos agropecuários, com 
quase $10 \%$ dos rendimentos destes agricultores $(9,20 \%)$. Nessa, inserem-se as rendas originárias do denominado "novo rural brasileiro" com as atividades rurais não agrícolas e a pluriatividade, tendo uma contribuição relevante nas receitas das famílias da "franja periférica".

Tabela 12. Composição das "Outras Receitas" obtidas pelos agricultores familiares do Grupo B do PRONAF no Rio Grande do Sul - 2006

\begin{tabular}{l|c|c}
\hline Fonte das outras receitas & $\begin{array}{c}\text { Valor } \\
(\mathbf{R} \mathbf{1 . 0 0 0})\end{array}$ & $\mathbf{\%}$ \\
\hline Aposentadorias e pensões & 270.538 & 84,96 \\
Programas sociais do governo & 6.596 & 2,07 \\
Salários recebidos pelo produtor em ativ. fora do estab. e outras receitas & 29.292 & 9,20 \\
Doações ou ajudas de parentes e amigos & 1.614 & 0,51 \\
Produtos da agroindústria & 2.502 & 0,79 \\
Pescado (capturado) & 132 & 0,04 \\
Desinvestimentos & 3.019 & 0,95 \\
Prestação de serviço para empresas integradoras & 3.763 & 1,18 \\
Prestação de serviço de benef. e/ou transf. prod. para terceiros & 276 & 0,09 \\
Atividades de turismo rural no estabelecimento & 102 & 0,03 \\
Outras ativ. Não agríc. realizadas no estab. (artesanato, tecelagem, etc.) & 519 & 0,16 \\
Exploração mineral & 78 & 0,02 \\
\hline Total & $\mathbf{3 1 8 . 4 3 1}$ & $\mathbf{1 0 0 , 0 0}$ \\
\hline Fonte: Tabulação especial da segunda apuração do Censo Agropecuário 2006 (IBGE/SIDRA, & 2012 ). \\
Nota: Dados organizados pelos autores. & &
\end{tabular}

Os programas sociais de transferência de renda, a exemplo do Bolsa Família, também ofereciam receitas às famílias mais fragilizadas de "pronafianos", embora com percentuais bem abaixo das fontes citadas anteriormente $(2,07 \%)$. De forma menos relevante, apareciam as receitas com prestações de serviços a empresas integradoras $(1,18 \%)$, como o caso do carregamento de animais em granjas integradas a estas empresas. Havia ainda receitas com desinvestimentos $(0,95 \%)$, com a agroindústria presente nas propriedades rurais $(0,79 \%)$, doações e ajudas de parentes e amigos $(0,51 \%)$, entre outras fontes de ingresso monetário em menores proporções.

Em suma, os indicadores relativos às receitas dos agricultores familiares do Grupo B do PRONAF evidenciam que, embora a produção agropecuária fosse importante, seus meios de vida eram fortemente determinados por estratégias não agropecuárias de reprodução social, onde o apoio do Estado representava um papel preponderante para sua continuidade nos espaços rurais. Por outro lado, as variáveis do Censo 2006 evidenciam que os agricultores familiares gaúchos de baixa renda gaúchos caracterizavam-se por maiores vulnerabilidades econômicas que os demais integrantes do segmento familiar no estado, devido à insuficiência do ativo que Ellis (2000) designaria como capital financeiro.

A única exceção, nesse caso, é a produção para o autoconsumo, que era mais representativa quando comparada com os demais agricultores. Mas o fato que não pode ser ignorado é que, sem as transferências públicas, dificilmente esses produtores continuariam vivendo no meio rural, sinalizando a necessidade do fortalecimento de estratégias de inserção produtiva e econômica que viabilizem oportunidades de trabalho decente como requisito indispensável à promoção do desenvolvimento humano das famílias pobres. Como as informações disponíveis no momento são escassas, tendo em vista o adiamento do Censo Agropecuário $2016^{10}$, os dados apresentados (também

\footnotetext{
${ }^{10}$ O novo Censo Agropecuário, com data de referência de 31 de dezembro de 2016, estava previsto para ser realizado no início de 2017. No entanto, a redução orçamentária levou o IBGE a adiar a referida pesquisa e sua realização está condicionada à liberação dos recursos necessários e a outro cronograma de atividades ainda não definido (IBGE, 2016).
} 
disponíveis por microrregiões e municípios) podem ser utilizados como referência para orientar a ação governamental nessa direção.

\section{Considerações finais}

Este trabalho procurou analisar a situação socioeconômica e produtiva dos agricultores familiares pobres do RS, segundo os critérios do PRONAF B, tendo como referência os dados do Censo Agropecuário de 2006. Esse segmento da agricultura familiar, embora pouco mencionado e até mesmo quase "invisível" nos meios acadêmicos e governamentais, era extremamente representativo, pois englobava um quarto dos estabelecimentos agropecuários do estado e envolvia mais de 228 mil pessoas, as quais apresentavam sérias fragilidades em seus processos de reprodução social. Em algumas das microrregiões sul rio-grandenses, os estabelecimentos do Grupo B ultrapassavam metade dos agricultores familiares e, para o território estadual como um todo, em média, quase $30 \%$ dos mesmos encontravam-se enquadrados nos limites desta categoria de "pronafianos".

O segmento de agricultores pobres possuía um estoque de ativos limitado, sobrevivendo com pouco capital natural, não conseguindo gerar excedentes econômicos das atividades agropecuárias suficientes à sua reprodução social de forma digna. Dessa forma, dependiam de outras receitas, especialmente aposentadorias e pensões e atividades não agrícolas dentro e fora do espaço rural. No que diz respeito ao capital físico, evidenciou-se que os agricultores do Grupo B pouco e, em alguns casos quase nada, utilizavam técnicas e equipamentos capazes de incrementar sua produção agrícola.

Quanto à dotação de capital financeiro, somente a produção para o autoconsumo apresentava-se relevante, por estar intimamente ligada aos processos de segurança alimentar e nutricional do próprio grupo doméstico, sendo estratégica a esta categoria. $\mathrm{O}$ capital social, entendido como o nível de organização em entidades coletivas, é outro recurso que assumia baixos percentuais junto ao segmento. Já o estoque de capital humano também era deficiente, especialmente quando se analisam variáveis como a idade avançada, os baixos níveis educacionais e a falta de apoio técnico aos chefes dos estabelecimentos de baixa renda.

Percebe-se, então, que a situação de pobreza dessa categoria de agricultores no meio rural do RS é multidimensional, perpassando por carências em vários componentes do pentágono de capitais constitutivo da plataforma de ativos, que, como foi discutido, é a base para ampliar as liberdades de escolha das famílias em situação de vulnerabilidade social. Isso permite afirmar que esses agricultores necessitam de melhorias substanciais na quantidade e na qualidade de seu estoque de ativos/capitais, bem como em suas capacitações humanas individuais, para que possam ampliar e fortalecer seus meios de vida e, dessa forma, ingressar em um processo de superação do ambiente de privações em que vivem.

Portanto, em face do quadro de "múltiplas carências produtivas" retratado, infere-se que o público pesquisado necessita de políticas e ações que favoreçam um leque variado de estratégias de reprodução social e de sobrevivência, sejam elas agrícolas ou não agrícolas, objetivando abarcar a sua grande heterogeneidade socioeconômica. Esse e outros aspectos merecem ser considerados em qualquer plano estratégico, visando fortalecer as capacidades dos agricultores pobres para que eles possam atuar como agentes do processo de mudança social e não apenas como receptores passivos da ajuda governamental. Assim, novos estudos sobre esta temática poderão ajudar a verificar até que ponto iniciativas recentes, a exemplo do Plano Brasil 
sem Miséria e do Programa de Territórios da Cidadania, contribuíram e/ou estão contribuindo de forma efetiva para enfrentar esse desafio no campo gaúcho.

\section{REFERÊNCIAS}

ALVES, E.; ROCHA, D. P. Ganhar tempo é possível? In: GASQUES, J. G.; VIEIRA FILHO, J. E. R.; NAVARRO, Z. A agricultura brasileira: desempenho, desafios e perspectivas. IPEA, 2010, p.275-290.

ANDERSON, J. S. N.; SCHNEIDER, S. Brazilian demographic transition and the strategic role of youth. Espace populations sociétés. N. 2-3, p 1-20, 2014.

AQUINO, J. R. et al. Dimensão e localização do público potencial do PRONAF "B" no Brasil: uma análise a partir do Censo Agropecuário 2006. In: CONGRESSO BRASILEIRO DE ECONOMIA, ADMINISTRAÇÃO E SOCIOLOGIA RURAL, 49, 2011, Belo Horizonte/MG. Anais... Belo Horizonte/MG: SOBER, 2011. (CD-ROM). AQUINO, J. R. et al. Dimensão e características do público potencial do Grupo B do PRONAF na região Nordeste e no estado de Minas Gerais. In: SCHNEIDER, S.; FERREIRA, B.; ALVES, F. (Orgs.). Aspectos multidimensionais da agricultura brasileira: diferentes visões do censo agropecuário 2006. Brasília/DF: IPEA, 2014. p. 77-105.

AQUINO, J. R.; LACERDA, M. A. D. Magnitude e condições de reprodução econômica dos agricultores familiares pobres no semiárido brasileiro: evidências a partir do Rio Grande do Norte. Revista de Economia e Sociologia Rural. Piracicaba/SP, Vol. 52, Supl. 1, p. 167-188, 2014.

BUAINAIN, A. M.; ALVES, E.; SILVEIRA, J. M.; NAVARRO, Z. Sete teses sobre o mundo rural brasileiro. Revista de Política Agrícola. Ano XXII, n 2, p. 105-121, abr./maio/jun. 2013.

CAMARANO, A. A.; ABRAMOVAY, R. Êxodo rural, envelhecimento e masculinização no meio rural: panorama dos últimos 50 anos. Revista Brasileira de Estudos Populacionais. Brasília, 15 (2), p. 45-65, 1998.

CASTRO, J. A. Dimensão e medição da pobreza extrema e a situação social e pobreza extrema no Rio Grande do Sul. Brasília: IPEA, 2011. 29p.

DELGADO, G.C. O setor de subsistência na economia brasileira: gênese histórica e formas de reprodução. In: JACCOUD, L. (Org.). Questão social e políticas públicas no Brasil contemporâneo. Brasília: Ipea, 2005. p. 19-50.

DEL GROSSI, M. E.; MARQUES, V. P. M. A. Agricultura familiar no censo agropecuário 2006: o marco legal e as opções para sua identificação. Estudos Sociedade e Agricultura. Rio de Janeiro, v. 18, n. 1, p. 127-157, abr./2010.

DEL GROSSI, M. E. Agricultura familiar no Censo Agropecuário 2006. (Documento em formato PowerPoint apresentado no $49^{\circ}$. Congresso da Sociedade Brasileira de 
Economia, Administração e Sociologia Rural, realizado na cidade de Belo Horizonte/MG, 2011).

ELLIS, F. Rural livelihoods and diversity in developing countries. Oxford: Oxford University, 2000.

ESTEVAM, D. O.; MIOR, L. C. (Orgs.). Inovações na agricultura familiar: as cooperativas descentralizadas de Santa Catarina. Florianópolis: Editora Insular. 2014.

FAO/INCRA. Diretrizes de Política Agrária e Desenvolvimento Sustentável. Brasília, Versão Resumida do Relatório Final do Projeto UTF/BRA/036, 1995.

Novo retrato da agricultura familiar: o Brasil redescoberto. Brasília, 2000.

FREITAS, T. A diversificação dos meios de vida como expansão das capacitações: por uma Sociologia das Condições de Vida na fumicultura no Rio Grande do Sul. 2015. 326f. Tese (Programa de Pós-Graduação em Sociologia) - Universidade Federal do Rio Grande do Sul - UFRGS, Porto Alegre, 2015.

GRANDO, M. Z. Um retrato da agricultura familiar gaúcha. Porto Alegre: Fundação Estadual de Economia e Estatística, 2011, 21p. (Texto para Discussão FEE, nº 98).

GRISA, C.; GAZOLLA, M.; SCHNEIDER, S. A "produção invisível” na agricultura familiar: autoconsumo, segurança alimentar e políticas públicas de desenvolvimento rural. Revista Agroalimentaria. Venezuela, vol. 16, $\mathrm{n}^{\mathrm{o}}$ 31; p. 65-79, julio-diciembre 2010.

GRISA, C.; SCHNEIDER, S.; CONTERATO, M. A. A produção para autoconsumo no Brasil: uma análise a partir do Censo Agropecuário 2006. In: SCHNEIDER, S.; FERREIRA, B.; ALVES, F. Aspectos multidimensionais da agricultura brasileira: diferentes visões do Censo Agropecuário 2006. Brasília: IPEA, 2014, p.165-186.

GRISA, C.; SCHNEIDER, S. Três Gerações de políticas públicas para a agricultura familiar e formas de interação entre sociedade e Estado no Brasil. Revista de Economia e Sociologia Rural. Piracicaba/SP, Vol. 52, Supl. 1, p. 125-146, 2014.

IBGE. Censo Agropecuário 2006. Agricultura Familiar. Primeiros resultados. Brasil, Grandes Regiões e Unidades da Federação. Brasília/Rio de Janeiro: MDA/MPOG, 2009.

Nota Informativa: corte no orçamento inviabiliza realização do Censo Agropecuário em 2017. Rio de Janeiro: IBGE, 2016. Disponível em: <http://www.ibge.gov.br/home/disseminacao/destaques/2016_04_18_comunicado_cens o_agropecuario.shtm>. Acesso em: 18 abr. 2016.

IBGE/SIDRA. Censo Agropecuário 2006: agricultura familiar - MDA/PRONAF (Lei n ${ }^{\circ}$ 11.326 de 24/07/2006). Rio de Janeiro: IBGE, 2012. Disponível em: <http://www.sidra.ibge.gov.br/bda/pesquisas/ca/defaultMDA.asp?z=p\&o=2\&i=P > Acesso em: 10 jan. 2015. 
KAGEYAMA, A. A.; BERGAMASCO, S. M. P. P.; OLIVEIRA, J. A. Uma tipologia dos estabelecimentos agropecuários do Brasil a partir do Censo 2006. Revista de Economia e Sociologia Rural. Piracicaba/SP, v. 51, n. 1, p. 105-122, jan./mar. 2013.

MATTEI, L. Mudanças nas regras de financiamento do PRONAF. Artigos mensais $O P P A$. Rio de Janeiro/UFRRJ/CPDA, n. 17, p. 1-4, mar. 2008.

MDA/SAF. Plano Safra da agricultura familiar 2006/2007. Brasília: MDA/SAF, 2006. Disponível em: <http://www.mda.gov.br>. Acesso em: 22 nov. 2006.

NIEDERLE, P. A.; FIALHO, M. A. V.; CONTERATO, M. A. A pesquisa sobre agricultura familiar no Brasil: aprendizagens, esquecimentos e novidades. Revista de Economia e Sociologia Rural. Piracicaba/SP, Vol. 52, Supl. 1, p. 9-24, 2014.

OLIVEIRA, D.; GAZOLLA, M.; SCHNEIDER, S. Produzindo novidades na agricultura familiar: agregação de valor e agroecologia para o desenvolvimento rural. Cadernos de Ciência \& Tecnologia. Brasília, v. 28, n. 1, p. 17-49, jan./abr. 2011.

PERONDI, M. A.; SCHNEIDER, S. Bases teóricas da abordagem de diversificação dos meios de vida. REDES. Santa Cruz do Sul, v. 17, n. 2, p. 117-135, maio/ago. 2012.

PERONDI, M. A. A teoria das capacitações nos estudos sobre os meios de vida e desenvolvimento rural. In: CONTERATO, M. A.; RADOMSKY, G. F. W.; SCHNEIDER, S. (Orgs.). Pesquisa em desenvolvimento rural: aportes teóricos e proposições metodológicas - volume I. Porto Alegre: Editora da UFRGS, 2014. p. 95115.

PICOLOTTO, E. L. Os atores da construção da categoria agricultura familiar no Brasil. Revista de Economia e Sociologia Rural. Piracicaba/SP, Vol. 52, Supl. 1, p. 63-84, 2014.

SCHNEIDER, S.; FIALHO, M. A. V. Pobreza rural, desequilíbrios regionais e desenvolvimento agrário no Rio Grande do Sul. Teoria e Evidência Econômica. Passo Fundo/RS, v. 8, n. 15, p. 117-149, 2000.

SCOONES, I. Livelihoods perspectives and rural development. Journal of Peasant Studies, v. 36, n. 1, p. 171-196, January 2009. Disponível em: <http://dx.doi.org/10.1080/03066150902820503>. Acesso em: 13 dez. 2015.

Sustainable livelihoods and rural development. Rugby, Warwickshire, UK: Practical Action Publishing, 2015.

SEN, A. Poverty and famines: essay on entitlement and deprivation. Oxford: Oxford University Press, 1981.

Desenvolvimento como liberdade. Tradução Laura Teixeira Motta. São Paulo: Companhia das Letras, 2000.

Desigualdade reexaminada. Rio de Janeiro: Record, 2001. 
WANDERLEY, M. N. B. O mundo rural como um espaço de vida: reflexões sobre a propriedade da terra, agricultura familiar e ruralidade. Porto Alegre: Editora da UFRGS, 2009. (Série Estudos Rurais).

Franja periférica, pobres do campo, camponeses: dilemas da inclusão social dos pequenos agricultores familiares. In: IV Colóquio Agricultura Familiar e Desenvolvimento Rural. Porto Alegre: PGDR/UFRGS, 2014. 21p. (Versão preliminar).

WAQUIL, P. D. As especificidades regionais e socioculturais da pobreza rural na região Sul do Brasil. In: BUAINAIN, A. M.; DEDECCA, C. (Orgs.). A nova cara da pobreza rural: desenvolvimento e a questão regional. Brasília: IICA, 2013. p. 355-398. (Série Desenvolvimento Rural Sustentável, v. 17).

ZUANAZZI, P. T.; BANDEIRA, M. D. Projeções populacionais do estado do Rio Grande do Sul para o período 2015-2050. Indicadores Econômicos FEE. Porto Alegre, v. 40, n. 3, p. 7-20, 2013.

Submetido em 26/09/2015

Aprovado em 07/05/2016 


\section{Sobre os autores}

\section{Joacir Rufino de Aquino}

Mestre em Economia Rural e Regional (UFCG). Professor Adjunto IV da Universidade do Estado do Rio Grande do Norte (UERN).

E-mail: joaciraquino@yahoo.com.br

\section{Marcio Gazolla}

Doutor em Desenvolvimento Rural (PGDR/UFRGS). Professor da Universidade Tecnológica Federal do Paraná (UTFPR). Endereço: UTFPR - Campus Pato Branco. Programa de Pós Graduação em Desenvolvimento Regional (PPGDR).

E-mail: marciogazolla1@gmail.com

\section{Sergio Schneider}

Sociólogo. Mestre e Doutor em Sociologia. Atualmente Academic Visitor no Centre for Food Policy, City University London/UK. Professor de Sociologia do Desenvolvimento Rural e Estudos Alimentares na Universidade Federal do Rio Grande do Sul, membro dos Programas de Pós-Graduação em Sociologia (PPGS) e Desenvolvimento Rural (PGDR). Bolsista PQ/CNPq/Brasil.

E-mail: schneide@ufrgs.br. 